\title{
The Transformation from civic consciousness to cultural confidence -- based on the analysis of college students' cultural confidence
}

\author{
Zeng Shi ${ }^{1}$ Yuan $\mathrm{Hu}^{2}$ \\ 1Jingdezhen Ceramics Institute,Jingdezhen, jiangxi, China \\ ${ }^{2}$ Jingdezhen Ceramics Institute, Jingdezhen, jiangxi, china \\ Liu Weiwei
}

Keywords: Citizenship, Cultural confidence, College students

\begin{abstract}
Absrtact: Cultural self-confidence is an important part of a country's comprehensive national strength, and also plays an important role in the healthy growth of college students. However, there is a certain degree of lack of cultural self-confidence in our country, so strengthening college students ' cultural self-confidence becomes an urgent task. Therefore, this article from the perspective of civic consciousness as the starting point, combined with the current situation of Chinese college students ' cultural self-confidence to cultivate college students civic awareness, thereby enhancing cultural self-confidence put forward the countermeasures.
\end{abstract}

\section{由公民意识向文化自信的转变 基于对大学生文化自信的分析}

\author{
石 增 ${ }^{1}$, 胡 远 $^{2}$ \\ ${ }^{1}$ 景德镇陶瓷大学，江西省景德镇市 \\ 2景德镇陶瓷大学, 江西省景德镇市
}

刘伟伟

关键词：公民意识；文化自信；大学生

摘要：文化自信是一个国家综合国力的重要组成部分，对大学生健康成长也有重要作用。然 而目前我国一定程度存在大学生缺乏文化自信, 因此, 加强大学生文化自信便成为了一个迫 切的任务。为此, 本文从公民意识这一视角为出发点, 结合当前我国大学生文化自信现状对 培养大学生公民意识、从而增强文化自信提出了对策分析。

1. 引言

在当前文化发展占主流的社会，一个国家的发展与否与这个国家的公民是否具有高度的 文化自信有着密切联系, 也是一个大国兴衰的关键。而在我国, 当代大学生身上承担有建设 社会主义文化强国的重任, 要增强大学生文化自信首先要树立强烈的公民意识, 要有勇于担 当建设文化强国的使命感和责任感[1]。强烈的公民意识有利于增强文化自信, 树立文化自觉, 从而增强自身对国家文化的归属感，这对当代大学生树立文化自信有着关键性作用。

2.结合公民意识对当前我国大学生文化自信的现状分析

虽然当前我国综合国力显著增强, 文化软实力也得到较大提高, 但我国大学生仍普遍存 
在文化自卑, 对自己国家的文化没有认同感, 究其根源, 这种现象与严重缺乏公民意识有着 较大联系。从不同意识层面来看, 主要表现为:

\section{1 公民意识中的国家意识层面}

国家意识是公民对本国的政治、经济、历史、文化和国情的了解基础上建立的一种主人 翁意识, 它是一种强烈的归属感和认同感。它具有强大的文化影响力, 是公民生产生活的精 神支柱。这主要体现在公民要认同祖国文化的价值所在, 并自觉承担起传承文化和传播文化 的历史使命, 这是文化自信的具体体现。公民具有强烈的国家意识, 这不仅能增强公民的文 化自信, 更能激发公民的爱国主义情感, 从而形成一种国家内部的强有力的精神支柱, 推动 整个民族的发展。

\section{2 在公民道德意识层面}

在今天人们提到文化，无疑脑中就会想到道德这一层面，文化的发展有其自身的前提， 无论是价值观还是道德体系, 都是规范人们行为使其活动具有文化性的一个过程, 也就是人 们理想追求的层面。文化自信, 无非就是把文化融合到自身, 再以实践的形式去把它表现出 来, 外化为具体的行为活动。公民道德意识是指公民关注社会事务, 具有履行政治权利和政 治义务意识的一种精神, 具体体现为社会道德。当这种社会道德在大学生公民中形成共鸣, 就会形成一种对中华民族文化的强烈认同感，从而真正做到理论上的文化自信。

\section{3 公民平等和宽容意识}

一个平等的社会是公民生产生活的良好基础, 公民的平等意识才铸就了一个平等的社会, 而当今社会并没有达到理想中的平等状态。究其原因, 在我国传统文化中, 从来就没有公民 这一说法, 古代的臣民观已经根深蒂固, 对当代大学生的思想造成了很大影响。尤其是今天 的社会, 许多大学生被古代封建传统思想中的忠孝、仁义、臣民、君权等思想观念所影响,

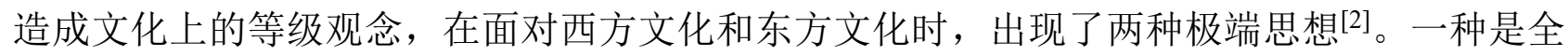
盘西化论, 认为西方的一切文化都是好的, 持肯定态度, 对中国文化则是完全否定; 另一种 则是本土论, 拒绝接受一切外来文化, 固步自封。面对这种情况, 大部分大学生缺乏自己的 见解, 容易陷入这样的文化圈套, 结果导致了文化自卑。

\section{3.从公民意识的视角分析大学生当前文化自信下降的缘由}

\section{1 个体文化自觉意识的缺失}

一方面, 当代大学生参与意识不强, 关注的只是个人的自我满足和小群体的利益, 没有 把国家这个大群体放在心中。因此多数大学生在进行社会活动的时候, 往往都是以个人利益 为出发点, 更有的是则表现为无参与意识, 存在着“事不关己, 高高挂起”的现象。这种价值 观显然与当代公民意识格格不入, 所以, 在建设社会主义文化的过程中, 对当代大学生的公 民意识进行教育就显得非常有必要。另一方面, 大学生公民责任心贵乏, 没有认识到自己在 国家中的主体地位。社会的发展离不开每一个群体, 需要每一个公民的助力, 因此, 大学生 这个群体在促进中国文化发展过程中起着决定性作用 ${ }^{[3]}$ 。而现实却是普遍大学生认为自己的 力量微不足道, 只需做好小我, 社会文化的发展与自己完全挂不上钩。这正是因为大学生没 有看到个人的意志对社会发展也有一定作用。

\section{2 社会的组织引导不足}

缺乏系统化、理论化的教育是导致大学生缺乏文化自信的主要因素。生活在当今社会的 大学生, 他们见过许多形形色色的社会问题, 社会上的一切好的、坏的现象都会对他们的世 界观、人生观、价值观产生影响, 从而导致对祖国文化的认识上的偏差。要想引导他们形成 
正确的三观, 能够正确认识祖国文化, 仅仅依靠学校理论上的教育远远不够。他们受到了家 庭、社会等生活环境的影响, 缺乏一个良好的社会文化氛围, 导致大学生在面临困境的时候 不能以正确的三观为标准来做出判断。这往往会导致他们产生怀疑, 从而更加对本国文化产 生不自信。

\section{4.促进大学生树立文化自信的对策建议}

\section{1 强化大学生公民责任感与参与感}

作为大学生, 必须意识到每个个人或群体都对社会发展起着重要作用, 都是文化的创造 者, 因此必须强化自己在社会中的主体意识。作为大学生, 随时随地应该以社会、国家的利 益为出发点, 把奉献社会和维系社会良好关系作为己任。公民的责任所在就是参与社会建设, 他们不仅是对本国文化的强烈认同, 更是作为一名公民该有的责任。主动承担起这份责任, 作为一个大学生应该有的公民意识, 才会自觉热爱国家文化, 从而在国家文化中提高自身的 文化自信。

\section{2 培养大学生的反思批判意识与世界公民的视野, 建立和谐的文化观}

任何事物都是在总结、反思以及批判的过程中发展的，文化的发展也不例外。例如，新 文化运动之所以能成功, 就在于他不断对自己历史的反思、对时代的反复认识、对所处社会 文化的不断批判。作为当代大学生, 在面临文化发展转型的重要时期, 不应消极被动、人云 亦云, 要不断思考, 积极主动的发挥自我创造力参与到文化建设中去 ${ }^{[4]}$ 。在这个过程中, 一 方面要增强反思批判能力, 正确认识外来文化和本土文化, 对于外来文化, 要虚心接受其优 秀的部分, 对于本土文化, 要取其精华, 去其糟粕; 另一方面, 要培养世界公民的视野, 将 个人行为放到世界范围内审视, 将本国文化推向世界中去, 有利于推动世界文化的发展。

\section{3 营造公民文化氛围, 以“走心”的有效措施引导大学生建立文化自信}

良好的文化氛围不仅能潜移默化的影响他人, 也能丰富自己的文化生活, 达到当代大学 生的文化精神要求。这需要政府机构、学校、各团体组织以及网络媒体等建立有效机制, 例 如, 让大学生参与到文化研讨会、社会文化实践活动中去, 充分了解文化发展的现状, 以便 更好推动文化全面发展，从而增强自身的文化自信。此外大众传媒更应积极建立健康和谐的 文化氛围，增强大学生文化自信。

\section{5. 总结}

公民意识在大学生增强文化自信过程中起着根本性和关键性作用。有了公民意识，每个 人才会自觉融入到建设社会主义文化中去, 积极主动的发挥自我创造力, 把文化建设当成一 种理所当然的任务, 认识到自己在文化建设中的基础性作用, 自我得到了发展, 文化自信也 就油然而生。因此, 要把公民意识全面灌入到大学生的血液中去, 在公民意识中完成建设文 化强国这一重大任务。

\section{致谢}

本文为 2017 年景德镇陶瓷大学研究生创新专项基金项目“95 后大学生对文化自信的认同 --以江西为例（JYC201710）的阶段性成果。

\section{References:}

[1] Zheng Qiujuan. A study on the current situation of college students' cultural self-confidence -based on the survey of colleges and universities in changzhou city [J]. Century 
bridge,2017(12):68-69.

[2] Ning manrong, Li bei. A study on the status of college students' cultural confidence in the context of network society [J]. New campus (early part), 2017(9):11-11.

[3] Deng xiangsheng. Reflections on improving the cultural confidence of college students [J]. Journal of wuhan institute of shipping technology, 2016(3):115-117.

[4] Bai xin. Thoughts on the cultivation of contemporary college students' cultural consciousness and cultural self-confidence from the perspective of cultural identity $[\mathrm{J}]$. Engineering technology research,2017(4):231-233. 